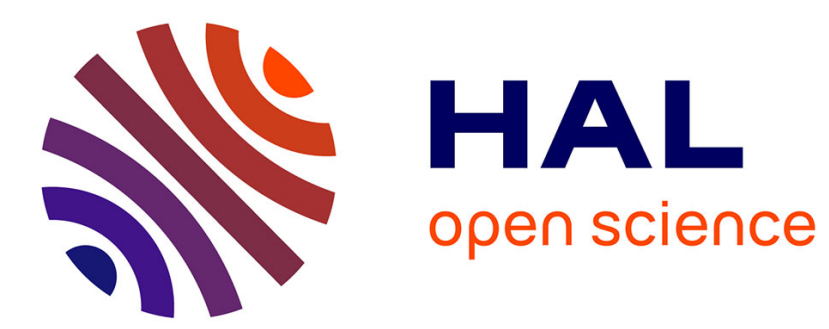

\title{
Missing Daughters, Missing Brides?
}

Hippolyte d'Albis, David de La Croix

\section{To cite this version:}

Hippolyte d'Albis, David de La Croix. Missing Daughters, Missing Brides?. 2012. halshs-00717385

\section{HAL Id: halshs-00717385 \\ https://shs.hal.science/halshs-00717385}

Submitted on 12 Jul 2012

HAL is a multi-disciplinary open access archive for the deposit and dissemination of scientific research documents, whether they are published or not. The documents may come from teaching and research institutions in France or abroad, or from public or private research centers.
L'archive ouverte pluridisciplinaire HAL, est destinée au dépôt et à la diffusion de documents scientifiques de niveau recherche, publiés ou non, émanant des établissements d'enseignement et de recherche français ou étrangers, des laboratoires publics ou privés. 


\section{Documents de Travail du Centre d'Economie de la Sorbonne}

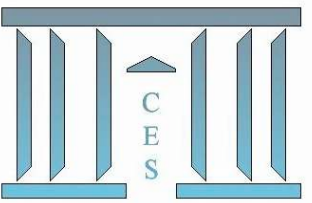

\section{Missing Daughters, Missing Brides ?}

Hippolyte d'AlBIS, David de la CROIX

2012.28

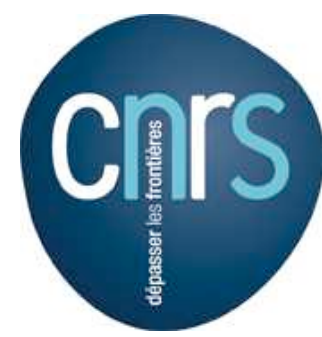




\title{
Missing Daughters, Missing Brides?
}

\author{
Hippolyte d'Albis* $\quad$ David de la Croix ${ }^{\dagger}$
}

April 14, 2012

\begin{abstract}
Even in countries where there is a male-biased sex ratio, it is still possible for the marriage market to be balanced if men marry younger women and population is growing. We define a missing Brides Index to reflect the intensity of the possible imbalance at steady state, taking into account the endogeneity of population growth. Taking international data on ages at marriage, fertility rate, and sex ratio at birth, we rank countries according to the Missing Brides Index.
\end{abstract}

JEL Classification Codes: J12, J13, J16.

Keywords: Missing women, marriage, fertility.

\section{Introduction}

Gender imbalance at birth is likely to have large social and economic consequences in South and East Asia. Among them, the marriage market could soon feature a large gap between the numbers of women and men, leaving a significant proportion of the latter without brides. In this article, we propose a simple formula that gives, for some key demographic characteristics, the gender imbalance on the marriage market in a permanent regime. Due to population growth and age difference between spouses, the gender imbalance at birth is not necessarily the same as the one at the age of marriage. Those characteristics along with the outcome of the marriage market are used to determine an endogenous growth rate of the population that is ultimately used to define our "Missing Brides Index".

The endogenous computing of the growth rate of population satisfies the consistency of the standard stable population model; this also constitutes our main departure with the recent

\footnotetext{
*Paris School of Economics, University Paris I, France. E-mail: dalbis@univ-paris1.fr.

${ }^{\dagger}$ IRES and CORE, Université catholique de Louvain, B-1348 Louvain-la-Neuve, Belgium. E-mail: david.delacroix@uclouvain.be. David de la Croix acknowledges the financial support of the Belgian French speaking community (ARC conventions 09-14018 on "Sustainability").
} 
contributions of Bhaskar (2011) (and its corrigendum in the May issue of the same journal) and Guilmoto (2012) who take the growth rate as an exogenous variable. We apply our formula to several Asian countries and compute the proportion of men without brides if all demographic parameters were kept fixed. For instance, we find that $14 \%$ of Chinese men and $4 \%$ of Indian men would not find a partner on the marriage market. This large difference between the two countries is due to the very low fertility rates in China and the small age gap at marriage.

\section{The Model}

We develop a simple model that proposes a formula linking some characteristics of a population with the outcome of the marriage market.

Time is continuous and denoted by $t$. Let us denote by $N_{t}^{w}$ and $N_{t}^{m}$, the numbers of women and men who are born at time $t$. The sex ratio at birth is constant and denoted by $\sigma \equiv N_{t}^{w} / N_{t}^{m}$. Each individual is supposed to either marry, at age $a^{w}$ and $a^{m}$ respectively for women and men, or remain single. If married, a women has $\beta$ children at age $a^{w}+\alpha$. Otherwise, she remains childless. Hence, $\beta$ is the total fertility rate of mothers and $a^{w}+\alpha$ is the mean age at childbearing. For simplicity, it is supposed that longevity is deterministic and that nobody dies before the childbearing age.

The marriage market is monogamous and we suppose that celibacy is never a choice. A time $t$, the number of marriages is:

$$
\min \left\{N_{t-a^{w}}^{w}, N_{t-a^{m}}^{m}\right\}
$$

We are looking for a condition that features a permanent gender imbalance on the marriage market by analyzing its relationship with the demographic growth rate. More precisely, we derive a condition such that $N_{t-a^{w}}^{w} \leq N_{t-a^{m}}^{m}$ for all $t$, which rewrites:

$$
n\left(a^{m}-a^{w}\right)+\ln \sigma \leq 0
$$

where $n$ is the growth rate of the population. It appears that a low sex ratio does not necessarily implies that men permanently exceed women on the marriage market. It may indeed be compensated by a large demographic growth rate and a large age differences between spouses. As younger cohorts are more numerous, inter-cohorts marriage may be sufficient to equilibrate the marriage market.

We now determine the permanent demographic growth rate as a function of the outcome of the marriage market. Let us first consider the case such that men exceed women, which implies 
that all women are married. In that case, the population of new born at time $t$ is linked to the population of new mothers, which is constituted by the women born at time $t-a^{w}-\alpha$, through the following relationship:

$$
N_{t}^{w}\left(1+\frac{1}{\sigma}\right)=\beta N_{t-a^{w}-\alpha}^{w}
$$

from which the demographic growth rate is deduced:

$$
n=\frac{\ln \beta-\ln \left(1+\frac{1}{\sigma}\right)}{a^{w}+\alpha} .
$$

Conversely, if the number of women exceed the number of men on the marriage market, the number of new mothers at date $t$ is given by the number of married men born at time $t-a^{m}-\alpha$ :

$$
N_{t}^{w}\left(1+\frac{1}{\sigma}\right)=\beta N_{t-a^{m}-\alpha}^{m}
$$

The exercise therefore assumes that if there are excess women, they bear no children. We obtain the following demographic growth rate:

$$
n=\frac{\ln \beta-\ln (1+\sigma)}{a^{m}+\alpha}
$$

We see that the outcome of the marriage market has an impact on the demographic growth rate that relies on different parameters. For instance, the age at marriage for women is a driving parameter only if men are more numerous. Moreover, the sex ratio at birth has an opposite impact on growth depending on which gender is more numerous. Let us now turn to our formula.

Proposition 1 The number of men permanently exceeds the number of women on the marriage market if and only if:

$$
\sigma\left(\frac{\beta}{1+\frac{1}{\sigma}}\right)^{\frac{a^{m}-a^{w}}{a^{w}+\alpha}} \leq 1
$$

Proof: By replacing (4) in (2), we obtain that: $N_{t-a^{w}}^{w} \leq N_{t-a^{m}}^{m}$ for all $t$, if

$$
\frac{\ln \beta-\ln \left(1+\frac{1}{\sigma}\right)}{a^{w}+\alpha}\left(a^{m}-a^{w}\right)+\ln \sigma \leq 0,
$$

or, equivalently, if (7) is satisfied. Conversely, by replacing (6) in (2) and rearranging the expression, we obtain that: $N_{t-a^{w}}^{w} \geq N_{t-a^{m}}^{m}$ for all $t$, if 


$$
\frac{a^{w}+\alpha}{a^{m}+\alpha}\left(\frac{\ln \beta-\ln \left(1+\frac{1}{\sigma}\right)}{a^{w}+\alpha}\left(a^{m}-a^{w}\right)+\ln \sigma\right) \geq 0
$$

The left-hand-side of inequality (7) represents the permanent share of married men within a cohort of men (i.e. $N_{t-a^{w}}^{w} / N_{t-a^{m}}^{m}$ ) if women are missing. Conversely, the share of married women if men are missing is given by:

$$
\frac{1}{\sigma}\left(\frac{1+\sigma}{\beta}\right)^{\frac{a^{m}-a^{w}}{a^{m}+\alpha}}
$$

Those indexes represent the permanent tension on the marriage market.

\section{Definition 1 (Missing Brides Index)}

The Missing Brides $M^{b}$ Index is computed as:

$$
M^{b}=\left\{\begin{array}{lc}
\frac{1}{\sigma}\left(\frac{1+\frac{1}{\sigma}}{\beta}\right)^{\frac{a^{m}-a^{w}}{a^{w}+\alpha}} & \text { if }(7), \\
\frac{1}{\sigma}\left(\frac{1+\sigma}{\beta}\right)^{\frac{a^{m}-a^{w}}{a^{m}+\alpha}} & \text { otherwise. }
\end{array}\right.
$$

\section{Application}

Let us now apply our formula to major Asian countries. We first need to assign numbers to the parameters, $\beta, a^{m}$ and $a^{w}, \sigma$, and $\alpha$.

To compute the fertility rate $\beta$ we take the Total Fertility Rate from the United Nations, ${ }^{1}$ for the year closest to 2000, and we multiply this rate by (1-infant mortality rate), where the infant mortality rate is the under-five mortality (both sexes combined) from the World Population Prospects $^{2}$ over the period 2000-2005.

The age at marriage $a^{m}$ and $a^{w}$ are obtained from the United Nations, ${ }^{3}$ as the singulate mean age at marriage (SMAM) for the year closest to 2000.

The sex bias $\sigma$ is computed as the Female population aged 10-14 divided by the Male population aged 10-14, where population sizes are taken from the World Population Prospects. By doing so, we take into account not only the gender bias at birth, but also the gender bias resulting

\footnotetext{
${ }^{1}$ Department of Economic and Social Affairs, Population Division (POP/DB/Fert/Rev2008).

${ }^{2}$ World Population Prospects: The 2010 Revision (United Nations).

${ }^{3}$ Department of Economic and Social Affairs, Population Division (POP/DB/Marr/Rev2008).
} 


\begin{tabular}{lccccc|c}
\hline \hline Country & $a^{m}$ & $a^{w}$ & $\beta$ & $\alpha$ & $\sigma$ & $M^{b}$ \\
\hline South Korea & 30.35 & 27.07 & 1.12 & 2.95 & 0.897 & 1.194 \\
China & 25.12 & 23.31 & 1.29 & 3.15 & 0.907 & 1.139 \\
Singapore & 29.97 & 26.50 & 1.25 & 3.62 & 0.935 & 1.134 \\
Japan & 30.81 & 28.58 & 1.21 & 1.47 & 0.952 & 1.092 \\
Thailand & 27.41 & 24.06 & 1.54 & 2.97 & 0.961 & 1.078 \\
India & 24.77 & 20.20 & 2.64 & 6.58 & 0.921 & 1.043 \\
Malaysia & 28.63 & 25.12 & 2.45 & 5.34 & 0.953 & 1.028 \\
Viet Nam & 26.63 & 23.28 & 2.03 & 4.03 & 0.976 & 1.024 \\
Sri Lanka & 27.60 & 23.76 & 2.26 & 4.98 & 0.965 & 1.022 \\
Mongolia & 25.69 & 23.67 & 1.79 & 4.70 & 0.996 & 1.012 \\
Indonesia & 25.95 & 22.54 & 2.46 & 5.52 & 0.969 & 1.008 \\
Myanmar & 26.35 & 24.54 & 2.35 & 5.75 & 0.985 & 1.006 \\
Nepal & 23.04 & 19.62 & 3.34 & 6.98 & 0.936 & 1.005 \\
Cambodia & 24.59 & 22.80 & 3.09 & 6.05 & 0.975 & 1.000 \\
Philippines & 26.10 & 23.19 & 3.46 & 5.68 & 0.956 & 0.993 \\
Pakistan & 26.35 & 22.35 & 3.53 & 7.87 & 0.957 & 0.975 \\
Lao & 24.69 & 21.67 & 4.19 & 6.33 & 0.970 & 0.958 \\
\hline \hline
\end{tabular}

Table 1: Missing Brides Index $M^{b}$ for selected Asian countries

from possible excess female mortality up to age 15 (Anderson and Ray (2010) weights the importance of the various sources of sex ratio imbalances.)

Parameter $\alpha$ is the mean age at childbearing from the United Nations (same source as $\beta$ ) for the year closest to 2000 , from which we subtracted the mean age at marriage for women.

Table 1 present the results, where the countries are ranked by Missing Brides Index. It indicates that the shortage of women will be particularly severe in South Korea and China, but also in Singapore, Japan and Thailand. We observe that a strongly biased sex ratio in the population, such as the one in India or in Nepal, does not necessarily imply a shortage of women on the marriage market if the mean age gap between the spouses is large enough and if population is growing fast enough. Some counterfactual exercises can be conducted by the interested reader using the online simulation tool at: http://www.de-la-croix.be/missing-brides-index.html

Notice that the exercise conducted here is a steady state exercise. It computes marriage market imbalances in the long run, assuming that population growth corresponds to that determined by the marriage market situation. At the same time, the empirical estimates assume that the current values of key parameters (such as fertility) remain fixed. 


\section{Conclusion}

Our Missing Brides Index brings a richer information than the simple sex ratio. It takes into account key demographic factors such as the ages at marriage, and the total fertility rate. It also consider the growth rate of the population as endogenous and affected by the possible shortage of women. Finally, it can easily be computed from simple statistics.

\section{References}

Anderson, Siwan, and Debraj Ray. 2010. "Missing Women: Age and Disease." Review of Economic Studies 77 (4): 1262-1300 (October).

Bhaskar, V. 2011. "Sex Selection and Gender Balance." American Economic Journal: Microeconomics 3 (1): 214-44 (February).

Guilmoto, Christophe. 2012. "Skewed sex ratios at birth and future marriage squeeze in China and India, 2005-2100." Demography. forthcoming. 